\title{
A Verdade Lucreciana
}

Maria da Glória Novak

Universidade de São Paulo

NOVAK, M. G. A verdade lucreciana. Classica, Belo Horizonte, $3: 68-79,1990$.

RESUMĒ: Le De rerum natura nous expose la physique de l'univers. Or, il y a dans la nature un système, une ratio, c'est-à-dire, des lois contre lesquelles rien ne sert de Iutter, nous n'avons aucune prise sur elles. Si les hommes savaient contempler la nature et la comprendre, ils se libéreraient de la terreur et des ténèbres de l'esprit. S'ils ne le savent pas, s'ils ne le peuvent ou ne le veulent pas, ils seront quand-même libérés par la mort, car tout revient au sommeil et à la quiétude. C'est ce que déterminent la face de la nature et son système: naturae species ratioque.

O ponto de partida da filosofia epicúrea é a verificação da infelicidade humana. Todo homem quer ser feliz: mas, ignaro, constrói sobre bases falsas a sua felicidade e sofre.

Ora, diz o Mestre que o prazer é o princípio e o fim da própria vida e que o desejamos quando a sua ausência nos faz sofrer (Men. $\S$ 122.127-32). E distingue desejos naturais e desejos vazios. $\mathrm{Diz}$ que, dentre os naturais, uns são apenas naturais; outros necessários; e, dentre estes, uns são necessários para a felicidade, outros para a ausência de perturbação do corpo, outros para a própria vida (Sent. Vat. 33; cf. Lucr. II 16-9). Os vazios não são nem naturais nem necessários mas nascem da opinião: têm a sua origem na vida social e são insaciáveis, pois caem no ilimitado ( $K D$ XXIX-XXX; Lucr. V 1131-4.1432-3). Igualmente insaciável é o amor, e o sábio não se deixará dominar pela paixão (Lucr. IV 1058 et seqs). E distingue do prazer em movimento o prazer em repouso. Enquanto o primeiro lembra a noção de prazer de Aristipo de Cirene, 
consiste no segundo a verdadeira felicidade: ausência de perturbação no corpo e na alma (aponia e ataraxía. Cf. Usener 1966: fr. 2) . $E$, visto que nesses valores consiste o fim do viver feliz, neles deve apoiar-se toda escolha de prazer (Set. Vat. 21.71).

$\mathrm{O}$ instrumento verdadeiro da felicidade, o bom-senso (phrónesis Cf. Men. $\S 132 ; K D \mathrm{~V}$ ), condição sine qua non do viver em paz, princípio do qual provêm todas as outras virtudes, deve ser auxiliado pela memória (Her. $\S 35.82-3$; Pyth. $§ 84-5$ ), não só porque a posse da doutrina é sempre ameaçada e é preciso consolidá-la mas também porque a memória, sobre ser responsável pela formação de conceitos, pode também ser responsável pela felicidade do sábio em meio à dor (cf. D. L. X 22). Por sua causa, não apenas as dores da alma são maiores que as do corpo, igualmente são maiores os seus prazeres (D. L. X 137).

São, portanto, muito simples os valores do epicurismo: uma felicidade (eudaimonía) que consiste na ausência de perturbação do corpo e da alma, se atinge pela prática do bom-senso (Sent. Vat. 46.48) e se completa pela amizade. ${ }^{1}$

Ora, como pode o homem ser feliz se tem o coração pleno de medo? Assusta-o não só a idéia do nada post-mortem como também a idéia de que possa haver algo nesse post-mortem. Assustam-no os Deuses, nos quais vê seres temperamentais, sempre insatisfeitos e vingativos:

O primeiro passo da filosofia consistiria, pois, em livrá-lo dos seus temores: à morte, aos castigos do Aqueronte, aos Deuses.

Diz Epicuro na Carta a Heródoto ( $\$ 37$ ) que a atividade incessante da ciência da natureza garante à vida a serenidade perfeita. E diz o Autor do De rerum natura:

Nam ueluti pueri trepidant atque omnia caecis in tenebris metuunt, sic nos in luce timemus interdum nihilo quae sunt metuenda magis quam quae pueri in tenebris pauitant finguntque futura

(II 55-8 = III 87-90 = VI 35-8)

1

KD XXVII; Sent. Vat. 34.52.56; Lucr. V 1019-23. Apesar da opinião de Cícero ( De am. 9,19), a amizade epicúrea é um fim em si mesma, pelo prazer que proporciona, e nisso consiste a sua maior utilidade (v. Testard 1976:254). 
Assim como as crianças tremem e de tudo nas cegas trevas têm medo, assim nós, à luz, tememos às vezes perigos que em nada são mais temíveis do que aqueles com que as crianças nas trevas se apavoram

[e que imaginam iminentes;

e continua:

Hunc igitur terrorem animi tenebrasque necessest non radii solis neque luciäa tela diei discutiant, sed naturae species ratioque

(I $146-8=$ II 59-61 = III 91-3 $=$ VI 39-41)

Este terror, portanto, e estas trevas do espírito é necessário que os dispersem não os raios do sol nem as lúcidas setas no dia mas a vista da natureza e sua explicação.

Pois bem. O De rerum natura, sobre ser um poema contra o medo, é o poema da razão. Expõe, em versos brilhantes, a verdade da natureza, com vistas a livrar o homem dos seus temóres e a permitir-lhe o gozo da ataraxia: não é temível a morte, não são temíveis os Deuses, o Aqueronte não existe, os fenômenos que os homens atribuem aos Deuses derivam de causas naturais, e é preciso arrancá-los à ignorânciá geradora de crimes (III 37-40) pela explicação da natureza.

Primeiro. A morte nada é para nós (III 830) porque a alma é material e mortal. O Poeta insiste em prová-lo, com argumentos redundantes às vezes, sempre enfáticos. Se há ou não perfeita coerência lógica entre esses argurnentos, se não obedecem afinal a um plano perfeito, se compreendem vinte e oito, vinte e nove ou trinta provas da mortalidade, tudo isso não é o mais importante. O Poeta, enfim, transborda de idéias que corroboram a idéia mestra, e quase se poderia dizer que as foi lançando ao poema ao correr do cálamo, até chegar finalmente às fundamentais: a alma não tem as características da imortalidade e não está ao abrigo das causas de destruição.

Segundo. Não são temíveis os Deuses. Totalmente alheios à criação, à vida e à destruição dos mundos, eternos e bem-aventurados, levam existência tranquiila nos intermúndios e absolutamente não são os senhores ásperos que os míseros mortais imaginam e aos quais atribuem a onipotência. 
Ora, diz o Poeta, a não ser que o homem deixe de formar opiniões indignas dos Deuseś e alheias à sua paz, não conseguirá jamais, com plácido coração, a paz de espírito (VI 68-78) e não atingirá jamais a verdadeira piedade, que consiste em poder ver tudo com a mente em paz (V 1198-203).

Terceiro. Não são um castigo os fenômenos naturais. Os dois últimos livros do De rerum natura têm como objetivo maior livrar a mente humana do medo aos Deuses e à sua intervenção nos fatos da natureza: os fenômenos derivam de causas naturais, e o Poeta os explica um a um, salvaguardando a responsabilidade dos Deuses, a ataraxia divina.

Tal como é mortal o homem assim são mortais os mundos, e cairão em ruínas as muralhas ao seu redor (II 1144-5), obedecendo à lei natural: todos os compostos se decompõem e tudo se dissolve e volta aos corpos da matéria.

$\mathrm{E}$ este é o leitmotiv do De rerum natura.

Inicia-se o poema com imagens de vida e prazer; termina com tristes imagens de peste e luta e morte: criação e destruição, que o atravessam todo: eterna luta dos contrários sem vencido nem vencedor. Num ponto qualquer, entre criação e destruição, está o homem, cego, cheio de temor, ansiando pela glória, pela riqueza e pela imortalidade, vivendo nas trevas da ignorância e nos perigos da ambição, sem saber que a natureza nada mais quer para ele senão um corpo livre de dor e uma alma sem inquietude e sem medo (II 14-9).

O ciclo da vida, com o nascer e morrer a suceder-se como o dia e a noite, preocupou sempre os filósofos, ao menos desde o período arcaico na Hélade. Preocupou-os sempre a noção de que o mundo é feito de mudança; de que esta acarreta a morte e de que os seres uns dos outros se criam (Jaeger s.d.: 210-1; DIK 22 B 26 ; 31 B 8.17.20-1; 59 B 17; D. L. VIII 76).

Semelhante é a idéia no De rerum natura (I 54-7). O hino a Vênus e a peste de Atenas, em nítida oposição, parecem mostrar que tudo o que nasce está destinado a morrer. Contraste idêntico pontilha e equilibra o poema. Veja-se, por exemplo, o comentário do Poeta à exortação da natureza na prosopopéia do III livro: 
Cedit enim rerum nouitate extrusa uetustas semper, et ex aliis aliud reparare necessest [...] Materies opus est ut crescant postera saecla

"Aliás, cede sempre a velhice, empurrada pela mudança dos seres, e é necessário refazer uns dos outros [...] A matéria é necessária para que cresçam as gerações seguintes;

ou, no primeiro livro:

Haud igitur penitus pereunt quaecumque uidentur, quando alid ex alio reficit natura, nec ullam rem gigni patitur nisi morte adiuta aliensa

"Absolutamente, portanto, não perece até o âmago [tudo o que parece perecer, pois a natureza de um ser refaz outro e não permite o nascimento de coisa alguma a não ser ajudada [pela morte de outra";

ou

Nam quodcumque suis mutatum finibus exit, continuo hoc mors est illius quod fuit ante

(I $670-1=792-3=$ II $753-4=$ III 519-20)

“[ $[.$.$] tudo o que, mudado, sai dos seus limites$ acarreta imediatamente a morte do que antes existiu".

Até o século passado, ou seja, principalmente no século passado (e, por imitação, também neste) os estudiosos não se cansaram de assinalar no De rerum natura "uma desordem estrutural". Felizmente a imputação vem sendo anulada e agora se começa a entender - De rerum natura tal como se apresenta: e se apresenta perfeitamente estruturado, como provam, aliás, os cuidadosos estudos de Kenney, Minadeo e Cox.

Observa Minadeo (1969: 47-8) que os livros I, III, IV, V e VI começam com o tema da criação; I, II, III, IV e VI terminam com o tema da destruição, o que mostra perfeito equilíbrio estrutural no poema. 
E quando se diz que o De rerum natura é pleno de contrastes e oposições deve pensar-se em equilíbrio: à matéria opõe-se o vazio; à vida, a morte; à imortalidade dos semina, a mortalidade dos compostos.

$\mathbf{E}$ este equilíbrio que há na natureza é a ratio: essa é a lei da natureza, inerente a ela - é o sistema que impediu a terra de criar monstros (V 845-6); é o sistema segundo o qual os seres uns dos outros se criam. Ratio, equilíbrio, isonomia. $\mathrm{E}$ tudo volta aos corpos da matéria que são os únicos seres eternos - e eternos na sua unidade, na sua simplicidade: sunt igitur solida primordia simplicitate (I 548).

Pois bem. Aqui me pergunto qual o sentido da física lucreciana.

Epicuro, desde o início da Carta a Heródoto, recomenda, como vimos, uma atividade incessante da ciência da natureza, atividade que garante à vida uma serenidade perfeita (Her. $\$ 37$ ). Isto quer dizer que o conhecimento da natureza livra o homem das suas ilusões, dos seus medos, e dos seus desejos vazios.

\section{Como?}

Há dois modos de entendê-lo, exatamente como há dois modos de ler também o De rerum natura.

Primeiro, do ponto de vista religioso, como se lê na Carta a Pitocles: conhecendo-se as causas dos fenômenos naturais, excluem-se o mito e a ação dos Deuses, que impedem a serenidade ao homem; conhecendo as leis da natureza e a natureza dos Deuses, pode o homem tê-los por modelos e atingir a paz.

Segundo - e não por último —, é possivel entender as palavras do Mestre do ponto de vista científico.

Passei bastante tempo discutindo a expressão poesia didática. Duvidei da sua propriedade, afirmando que o De rerum natura que é sempre assim classificado - é primordialmente um poema, não um tratado de física.

Ora, o De rerum natura, um dos maiores monumentos da arte ocidental, é um tratado de física! Aliás, diz textualmente o Poeta que dissertará sobre o sistema superior do céu e dos Deuses e explicará os princípios das coisas (I 54-5). Poema que irradia 
luzes de gênio e de arte, como não pôde deixar de reconhecer o inimigo figadal do epicurismo, 2 sobre ser um livro ético é um tratado de física.

Não é, como pretenderam alguns estudiosos ao longo do tempo, a "mera reprodução de assuntos cósmico-filosóficos". $€$, sim, muito mais, a exposição de um sistema físico, exortação que visa a ensinar o homem a atingir a felicidade, não só pela consciência da sua própria dimensão de ser mortal, não só pela imitação dos Deuses imortais mas, antes e primeiro, pelo estudo e pela contemplação da física do universo: conhecê-la, entendê-la, aceitá-la: conhecer-se, entender a vida, aceitar a morte (cf. I 44-6.59-61; III 830).

A física de Epicuro e Lucrécio é a de Leucipo e Demócrito - o atomismo - . Também é de Demócrito, e é através de Nausífanes, que o Mestre aprendeu a teoria da ausência de temor religioso (athambie: DK 75 B 3; Cic. De fin. V 29,87).

Assim como o estoicismo, o epicurismo é uma doutrina de reconciliação do homem com a natureza. Tenta explicar o homem e o mundo por meio de um sistema que compreende uma lógica e uma física que levam a uma ética. Ensina critérios de certeza e regras de vida. Assim, tem objetivos morais: a definição do conceito de sábio e felicidade individual; e implica uma atitude religiosa. (Sobre a procura do bem, v. Arist. Eth. Nic. I 1 et seqs; DK 68 B 223).

São os seguintes os postulados básicos da filosofia lucreciana.

Primeiro, há “coisas" invisiveis (I 269-70) : e se a matéria pode ser invisivel, nem tudo o que é invisível, porém, é matéria; pode ser vazio (330): e esses são os dois componentes do universo (420).

Segundo, o vazio não tem limites (I 958-9): estende-se ao infinito em todas as direções (II 93).

Terceiro, a quantidade de matéria é infinita (I 1051) e é sempre a mesma (II 296).

2

Lucreti poemata ut scribis ita sunt, multis luminibus ingenii, multae tamen artis (Cic. Ad Q. fr. II 9,3). 
Quarto, a matéria compõe-se de corpos sólidos (I 510.548), que, pois, têm tamanho (II 384-5), peso (84) e forma (380) e são imutáveis (751-2), eternos ( $\mathrm{I}$ 485) e invisíveis (328). Inúmeras, mas não infinitas como pretendia Demócrito, são as suas formas (II 480); infinito, o seu número (523-5).

Esses corpos, a que Epicuro chamou átomoi e Lucrécio corpora prima, ou genitalia corpora ou rerum primordia ou semira rerum (I 55-61) não têm cor (II 815), odor, sabor, som, temperatura ou sensibilidade $(842-6)$.

E, enfim, nada vem do nada ( $\mathrm{I}$ 150) e nada acaba em nada (215-6), mas tudo volta aos semira rerum, segundo as leis da natureza (VI 43-5).

Os semina são os primeiros a mover-se por si mesmos (Prima mouentur enim per se primordia rerum II 133): combinam-se formando corpos diferentes, assim como se combinam as letras formando palavras diferentes.

Diz o Autor que os corpos através da água ou do ar aceleram a sua queda na razão direta do seu peso; que o mesmo, porém, não se dá no vazio: devem todos os átomos através do vazio mover-se com velocidade igual apesar da desigualdade do seu peso (II 230-42), porque no vazio nada os impele para o alto, e nenhum corpo só pela sua própria força (sua ui) pode elevar-se (185-6) . Ora, se todos os corpora prima "caem" com velocidade igual, como se produzem os choques (243-5)?

- E necessário que se afastem um pouco do seu rumo, apenas o mínimo possível, diz o Poeta.

Aqui a chave da física e da moral lucrecianas. Movem-se paralelamente os átomos no vazio infinito: movimento sempre igual. Eterno fluir. Repouso. Ausência de choques. Ausência de combinações. Ausência de mundos. Ausência de vida.

Mas esse fluxo eterno é perturbado no seu repouso. Em momentos incertos, em lugares incertos, átomos levados através do vazio pelo seu próprio peso desviam-se do seu rumo e esse desvio é o princípio do choque (II 217 et seqs).

Eis o quadro.

Primeiro, matéria em equilíbrio desde sempre até sempre: não é possível criá-la nem destruí-la, só é possível transformá-la. 
Segundo, fluxo dos átomos: movimento em repouso - mesmice do movimento.

Terceiro, desvio: um ângulo mínimo - o menor dos mínimos -: aqui e ali, em momentos incertos, em lugares incertos, rompe-se o repouso: um choque, outros choques, turbulência, combinações, compostos: nascimento dos mundos, vida.

Quarto, decomposição dos compostos. Volta ao fluxo inicial. Aí está. A vida é um acidente de percurso. Um acidente no próprio sentido etimológico. $\mathbf{E}$ vem de um ângulo infinitésimo e dura um átimo.

Exaustivamente o demonstra o Poeta: os compostos se decompõem; tudo é mortal exceto os Deuses e os primórdios dos seres. Tudo volta ao repouso: à ausência de vida, à morte imortal (mors inmortalis III 869).

O primeiro desvio, o primeiro choque acarretam outros choques, outros desvios. Assim também na vida humana: a primeira ilusão gera o primeiro erro e as ilusões e os erros sucedem-se em turbilhão. A primeira conquista exige outra e sempre outra, visto que uma após outra, sucessivamente, perdem o valor. Assim descreve o Autor a vida humana. Diz, por exemplo, no $\mathrm{V}$ livro, referindo a história dos primeiros homens:

nam facies multum ualuit uiresque uigebant.

Posterius res inuentast aurumque repertum quod facile et ualidis et pulchris dempsit honorem

(1112-4)

“[...] pois muito valor teve a beleza; $\mathrm{e}$ as forças prevaleciam. Posteriormente inventou-se a propriedade e descobriu-se o ouro, que tirou facilmente a honra aos fortes e aos belos";

Sic uoluenda aetas commutat tempora rerum. Quod fuit in pretio fit nullo denique honore

"Assim, com o rolar dos tempos, muda-se a situação das coisas. O que foi apreciado, acaba, afinal, sem nenhuma honra"; 
Nam quod adest praesto, nisi quid cognouimus ante suauius, in primis placet et pollere uidetur, posteriorque fere melior res illa reperta perdit, et immutat sensus ad pristina quaeque. Sic odium coepit glandis, sic illa relicta strata cubilia sunt herbis et frondibus aucta

$(1412-7)$

“Aliás, o que está à mão — se antes não conhecemos algo mais suave - agrada mais que tudo e parece importante; mas quase sempre uma coisa mais recente e melhor anula aquela descoberta e muda os sentimentos com relação a quaisquer bens primitivos. Assim começou a aversão às glandes; assim foram abandonados os leitos cobertos de relva e juncados de frondes".

$\mathrm{Na}$ origem da vida está um ângulo infinitésimo, um clinamen, graças ao qual o átomo apenas se afasta (nec plus quam minimum) do rumo original, no eterno fluir. Mas o homem não sabe permanecer ali, próximo ao repouso. Não sabe reconhecer um valor verdadeiro. Não sabe o que é o verdadeiro prazer: o recolhimento, um corpo sem dor, um espírito sem inquietação e sem medo. Quer ampliar o seu campo. Quer atingir os píncaros da glória.

Ora, a ampliação do campo é um movimento de descida. Ele desce. Amplia-se o turbilhão. Multiplicam-se os choques. Ele cai. "Lutando por subir à suma honra, percorre um caminho infausto, pois, do alto, o precipita a inveja", diz o Poeta (V 1123-6). Assim é que surgiram os reis (1108-9) e foram, depois, pisoteados pela turba (1139). E cada um procura a sua própria ruína, consumindo-se em vãs inquietações.

Todos sabemos que a física no epicurismo não é pura física mas física aplicada à felicidade. $\mathbf{E}$ o poema genial do mais genial dos discípulos de Epicuro segue o modelo da física e da vida: combinam-se as letras como se combinam os átomos. Formam-se corpos e palavras, e devem ter sentido para sobreviver. Vimos que a terra, em suas experiências de criação, tentou em vão dar monstros à luz: a natureza lhes impediu o crescimento ( $V$ 837-46). 
Mas permanece o lucreciano De rerum natura.

O Autor tem consciência de produzir uma obra de arte (IV 1-9), e tem consciência de agir em vários planos: o do invisível (rerum primordia pandam I 55), e o do visivel (solis cursus lunaeque meatus expediam V 76); e, ainda, em dois planos diferentes aí: o dos seres vivos e o das coisas desprovidas de alma, todos regidos por leis contra as quais nem a vontade sagrada pode lutar

nec sanctum numen fati protollere finis

posse neque aduersus naturae foedera niti

Age, ainda, naturalmente, no plano da sua criação poética. $\mathrm{E}$, de certo modo, cada plano reflete os outros. Por exemplo, a espontaneidade interna do átomo, que determina o clinamen e a vida, é uma força e como tal se deve entender. E assim como no início da vida está o clinamen, no início do poema está Vênus, o prazer, Vênus, força criadora.

$\mathrm{E}$ assim como os turbilhões se dissolvem no eterno fluir, e outros desvios poderão eternamente gerar outros turbilhões, assim também o poema vive a luta dos contrários:

Nec superare queunt motus itaque exitiales perpetuo, neque in aeternum sepelire salutem, nec porro rerum genitales auctificique motus perpetuo possunt seruare creata

(II 569-72)

" $\mathrm{E}$ assim os movimentos destruidores não podem vencer perpetuamente nem sepultar eternamente a vida, nem, por outro lado, os movimentos que criam e aumentam as coisas podem conservar perpetuamente as coisas criadas".

Ora, alternam-se criação e destruição, vida e morte, ao longo de todo o poema (cf., e.g., V 1289-96) .

$\mathbf{E}$ assim como fluem suavemente os átomos na eternidade e o seu fluxo é por vezes interrompido, assim como fluem as águas dos rios e aqui ou ali um desnivel lhes quebra a mansidão, assim 
como flui, cheia de percalços, a vida, assim também flui o De rerum natura. E, por sobre o fluxo tranqüilo da exposição do sistema físico, há desvios e digressões que se entrelaçam uns aos outros: turbilhão que compõe a exortação moral, presente em todo o poema .

Assim, nos prólogos dos seis livros, só para exemplificar, vê-se a humanidade esmagada sob o peso de uma superstição que a mantém cheia de medo e a leva ao crime (I 62) ; a humanidade esforçando-se noite e dia por atingir os cimos da opulência (II 12) ; a humanidade perturbada pelo medo à morte, que não lhe permite nenhum prazer límpido e puro (III 37; IV 38 [34]; a humanidade agitada de paixão, impudente e petulante, cheia de medo aos Deuses (V 45-8.73; VI 52), e sempre egoísta, ambiciosa, invejosa, falsa e traiçoeira. E o turbilhão.

Mas há como que uma força escondida (uis abdita quaedam $\mathrm{V}$ 1233) que esmaga os desejos dos homens: é a lei da natureza. Tudo volta à quietude, ao repouso, ao eterno fluir. Tudo. Não apenas o homem senão também as conquistas da civilização - as delícias da vida e o fastígio das artes, lindamente expostos no epílogo ao $\mathrm{V}$ livro; mesmo a Atenas de nome ilustre (praeclaro nomine) que abre o prólogo do VI livro: tudo. Realmente, o fim do $\mathrm{V}$ livro e o início do VI preparam o fim do poema: a peste de Atenas. Genetrix e Voluptas são os grandes termos do primeiro verso do De rerum natura; rixantes e corpora, os do último: nascer, lutar, morrer.

E o prólogo do segundo livro é o espelho humano do sistema físico superior. No alto as regiões serenas dos sábios, vida que apenas se afasta (nec plus quam minimum) do rumo original do eterno fluir. Abaixo, a turbulência das ondas, a turbulência dos combates guerreiros: os ventos que agitam as águas no grande mar, as ambições que agitam os homens no Campo de Marte. Míseras mentes humanas, que vivem nas trevas e que não vêem a natureza a exigir paz, a exigir a volta ao repouso eterno do eterno fluir.

Em suma, ao homem que vive cheio de medo nas trevas da ignorância indica o Poeta o caminho da libertação nestes três versos, que volto a citar, pois constituem o cerne da filosofia epicurista: 
Hunc igitur terrorem animi tenebrasque necessest non radii solis neque lucida tela diei discutiant, sed naturae species ratioque.

Naturae species ratioque: se o homem quiser, se souber contemplar e entender a natureza, livrar-se-á do terror e das trevas do espírito. Se não quiser, se não souber, será, ainda assim, libertado pela morte porque tudo volta ao sono e à quietude: assim o determinam a face da natureza e o seu sistema: naturae species ratioque.

Este, parece-me, é o sentido da física lucreciana: aqui a sua verdade. 


\section{BIBLIOGRAFIA}

\section{ObRas Especiais}

BERGSON, H. Philosophy of Poetry. New York, Philosophical Libr. [1959]. CARIOU, M. L'atomisme. Paris, A. Montaigne [1978].

CONCHE, M. Epicure: lettres et maximes. Paris, Ed. de Mégare, 1977.

COX, A. S. Lucretius and his Message: a Study in the Prologues of De Rerum Natura. Greece \& Rome, Oxford XVIII (1):1-16, Apr. 1971.

JAEGER, W. Paideia. São Paulo, Herder [s. d.].

KENNEY, E. J. Lucretius. Oxford, Clarendon, 1977.

MINADEO, R. The Lyre of Science. Form and Meaning in Lucretius' De Rerum Natura. Detroit, Wayne State Univ., 1969.

SANTAYANA, G. Tres poetas filósofos. Trad. de J. Ferrater Mora. Buenos Aires, Losada [1943].

SERRES, M. La naissance de la physique, dans le texte de Lucrèce. Paris, Ed. de Minuit [1977].

TESTARD, M. Les idées religieuses de Lucrèce. Bulletin de l'Association G. Budé, Paris, 1976 (3) : 249-72, juin-sep. 1976.

USENER, H. Epicurea. Stuttgart, B. G. Teubner, 1966.

\section{Textos}

CAVAlCANTE DE SOUZA, J. Ed. Os pré-socráticos. São Paulo; Abril Cultural, 1973.

DIELS, H.; KRANZ, W. Die Fragmente der Vorsokratiker, Berlin, Weidmann, 1954.

DIOGENES LAERTIUS, Lives of Eminent Philosophers. London, W. Heinemann -- Cambridge Mass., Harvard, 1959.

EPICURO (v. Conche, Usener).

LUCRECE. De la nature. Tex ét. \& trad. par A. Ernout. Paris, «Les Belles Lettres», 1971/1975. 2 v. 